\title{
Loss of Stat6 affects chromatin condensation in intestinal epithelial cells causing diverse outcome in murine models of inflammation- associated and sporadic colon carcinogenesis
}

\author{
Tiago De Oliveira $\mathbb{1}^{1} \cdot$ Mallika Ramakrishnan ${ }^{1} \cdot$ Michaela A. Diamanti ${ }^{1} \cdot$ Paul K. Ziegler $^{1} \cdot$ Frank Brombacher $^{2}$. \\ Florian R. Greten (10) 1,3
}

Received: 11 April 2018 / Revised: 16 August 2018 / Accepted: 28 September 2018 / Published online: 23 October 2018

(c) The Author(s) 2018. This article is published with open access

\begin{abstract}
While great advances have been achieved regarding the genetic basis of colorectal cancer, the complex role of cell-cell communication and cytokine-induced signaling during its pathogenesis remains less understood. Signal transducer and activator of transcription 6 (Stat6) is the main transcription factor of interleukin-4 (IL-4) signaling and its participation in the development of various tumor types has been already reported. Here we aimed to examine the contribution of Stat6 in intestinal epithelial cells (IEC) in mouse models of intestinal carcinogenesis. Wild-type (WT), Stat6 knockout (Stat6 ${ }^{-{ }^{-}}$), and intestinal epithelial cell-specific IL-4R $\alpha$ knockout $\left(I l-4 r \alpha^{\Delta \mathrm{IEC}}\right)$ mice were subjected to colitis-associated (AOM/DSS) and colitis-independent (sporadic) carcinogenesis. IEC proliferation, apoptosis and RNA expression were evaluated by immunohistochemical, immunoblot, and RT-PCR analysis. We found that Stat $^{-1-}$ mice developed more tumors in the colitis-associated carcinogenesis model. This was accompanied by a more pronounced inflammatory response during colitis and an elevated Stat3-dependent proliferation of IEC. Increased sensitivity to DSS-induced colitis was caused by elevated cell death in response to the initial carcinogen exposure as Stat6 deficiency led to increased chromatin compaction affecting DNA damage response in IEC upon treatment with alkylating agents independently of IL-4R $\alpha$ engagement. Thus, loss of Stat 6 caused more severe colitis and increased tumor load, however loss-of-initiated Stat6 ${ }^{-1-}$ IEC prevented tumor formation in the absence of overt inflammation. Our data unravel unexpected IL-4-independent functions of Stat6 in chromatin compaction in intestinal epithelial cells ultimately providing both tumor suppressive as well as tumor promoting effects in different models of intestinal tumorigenesis.
\end{abstract}

Electronic supplementary material The online version of this article (https://doi.org/10.1038/s41388-018-0551-2) contains supplementary material, which is available to authorized users.

Florian R. Greten

greten@gsh.uni-frankfurt.de

1 Institute for Tumor Biology and Experimental Therapy, GeorgSpeyer-Haus, 60596 Frankfurt, Germany

2 International Centre for Genetic Engineering and Biotechnology and University of Cape Town and South African Medical Research Center external Unit, Anzio Road, Observatory, 7925 Cape Town, South Africa

3 German Cancer Consortium (DKTK) and German Cancer Research Center (DKFZ), 69120 Heidelberg, Germany

\section{Introduction}

In spite of the remarkable clinical advances in cancer diagnosis and treatment achieved in the last decades, colorectal cancer continues to be an important cause of mortality worldwide with $\sim 700,000$ deaths reported yearly [1]. Thus, an exact understanding of the molecular mechanisms involved in its pathogenesis is crucial for the improvement of new therapeutic strategies. Deciphering the mutational landscape that controls oncogenic signaling in tumor cells is one pre-requisite for this. However, signaling induced by the tumor microenvironment controlling cell fate decisions as well as polarization of inflammatory immune cells also play an equally important role during all stages of tumorigenesis [2]. Depending on the prevailing polarization of T cells $\left(T_{H} 1, T_{H} 2, T_{H} 17\right.$, etc.), macrophages (M1 and $\left.M 2\right)$ and neutrophils (N1 and $\mathrm{N} 2$ ) the tumor microenvironment can provide both tumor promoting or tumor suppressive 
signals [3]. Importantly, the decision whether the microenvironment is shifted toward a more tumor suppressive or tumor promoting milieu depends on cytokine-induced signaling. One of the most prominent signaling pathways responsible to skew immune cells towards a presumably tumor promoting type 2 profile comprises IL-4 receptor engagement and subsequent activation of signal transducer and activator of transcription 6 (STAT6) [4]. IL-4 as well as IL-13 use the common $\gamma$-chain $(\gamma c)$-related IL-4 receptor $\alpha$ chain (IL-4R $\alpha)$ to signal through three cytokine-receptor combinations: IL-4 signals through the type I receptor IL$4 \mathrm{R} \alpha-\gamma \mathrm{c}$, and both IL- 4 and IL-13 can signal through the type II receptor IL-4R $\alpha-$ IL-13R $\alpha 1$ [5]. Expression of the type I receptor is restricted to immune cells while the type II receptor is also found in other cell types, including epithelial cells [5-10]. Both IL-4 and IL-13 induce JAKdependent tyrosine phosphorylation of the receptor and subsequent STAT6 phosphorylation. Phosphorylated STAT6 dimerizes and translocates to the nucleus where it exerts its canonical functions regulating the transcription of IL-4 target genes [11]. The influence of STAT6 on immune cell regulation and its association with different types of malignancies, including colorectal cancer, has been already investigated [12-17]. In an IL-4-dependent manner Stat6 has been suggested to promote colorectal cancer due to its ability to polarize myeloid cells in a wound-healing/tumorpromoting alternative phenotype, which differentiates these cells from the tumor-suppressing IFN $\gamma$-mediated classical activation phenotype [18]. However, whether Stat6 in intestinal epithelial cells can also directly contribute to colon carcinogenesis has not been fully addressed yet.

Using genetically modified mice and different wellestablished cancer models we show that Stat6 affects chromatin condensation in intestinal epithelial cells thereby interfering with alkylation-induced DNA-damage response and p53 activation independently of its canonical IL-4 signaling functions. Consequently, Stat6 suppresses colitisassociated tumorigenesis, protecting the intestinal epithelium from apoptosis and severe tissue damage. In stark contrast, in a model of sporadic inflammation-independent carcinogenesis this Stat6 controlled mechanism supports tumor promotion highlighting a so far unrecognized nuclear function of unconventionally activated Stat6 in IEC.

\section{Results}

\section{Stat6 suppresses colitis-associated tumorigenesis}

To determine Stat6 function during colitis-associated carcinogenesis, we subjected animals from both genotypes to the well-established AOM/DSS model [19, 20]. Loss of Stat6 rendered mice very susceptible to chronic colitis which caused significantly more weight loss in Stat $^{-1-}$ mice compared to control mice after the second DSS cycle (Fig. 1a). Weight loss became even more pronounced in Stat6-deficient mice after the third cycle requiring early termination of the model on day 57. In line with a more severe form of colitis, histological analysis revealed increased tissue damage and epithelial ulceration in $\mathrm{Stat6}^{-1-}$ mice (Fig. 1b, c). Moreover, the number as well as the size of colonic tumors was significantly higher in $\mathrm{Stat}^{-/-}$mice (Fig. 1d-g). Tumors from both genotypes were located exclusively in the colon and exhibited classical tubular morphology with moderate dysplasia.

To directly confirm increased susceptibility to DSSinduced colitis, we examined the acute inflammatory response in WT and $\mathrm{Stat6}^{-1-}$ mice after the first cycle of DSS on day 15 of the colitis-associated carcinogenesis (CAC) model. Indeed, Stat6 deletion led to more pronounced tissue damage (Fig. 2a-c) and increased expression of genes encoding pro-inflammatory cytokines $I L-1 \beta$, Ptgs2, IL-6, and IL-11 as well of the chemo-attractants Cxcll, Cxcl2, Ccl3, and Ccl2 in colonic mucosa (Fig. 2d). Considering Stat6 the main transcription factor downstream of IL-4 receptor engagement, which has been associated with M2 macrophage polarization [21], we aimed to evaluate in Stat6-deficient inflamed mucosa the expression of genes typically expressed upon M2 polarization. Surprisingly, real-time PCR analysis did not reveal any significant reduction in $\mathrm{Arg} 1, \mathrm{Mrc}$, Dectin-1, $\mathrm{Yml}$ or $\mathrm{IllO}$ expression in DSS-challenged Stat $^{-1-}$ mice compared to WT animals (Fig. 2e). Moreover, only moderate yet non-significant differences were found in the expression of M1-associated genes, such as Tnfo, iNos, Ifn $\gamma$ as well as IFN $\gamma$-regulated genes between the two genotypes on day 15 of the AOM/ DSS regimen (Fig. 2f and Figure Supp. 1A). Importantly, however, in agreement with elevated Il6 and Ill1 gene expression in Stat6-deficient DSS-challenged mucosa, tyrosine-phosphorylated STAT3 (Y705) was markedly enhanced in Stat ${ }^{-1-}$ IEC (Fig. 2g, h and Figure Supp. 1B). Previously, we had reported that epithelial regeneration during acute colitis was dependent on Stat 3 activation in IEC [22]. In line with this notion, Stat $6^{-l-}$ IEC proliferated significantly more during the healing phase of acute colitis (Fig. 2i, j). Importantly, also Stat6-deficient tumor epithelia were characterized by increased Stat3 phosphorylation suggesting that enhanced gp130-dependent Stat 3 activation triggered by IL- 6 and IL- 11 could account for the proproliferative, pro-tumorigenic phenotype of Stat $^{-1-}$ mice (data not shown). To confirm this, we generated Stat ${ }^{3 \mathrm{IEC}}$; Stat $^{-1-}$ double mutants and analyzed IEC proliferation on day 15 of the AOM/DSS model. Expectedly, absence of Stat3 reduced proliferation in Stat6-deficient IEC, which led to even further impairment of epithelial regeneration and massive crypt loss when compared to Stat6-single mutants 
A

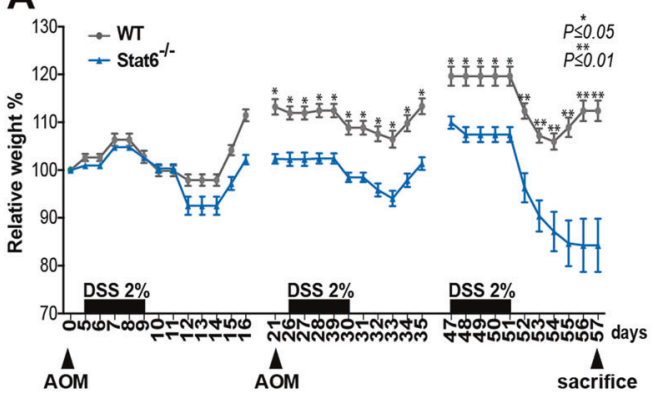

D

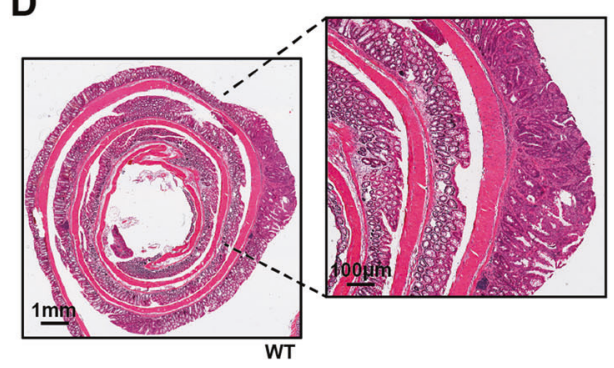

B

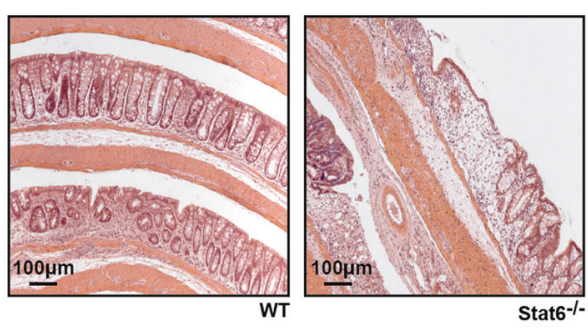

C

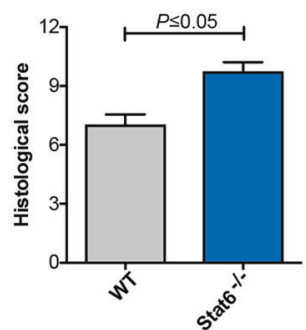

E

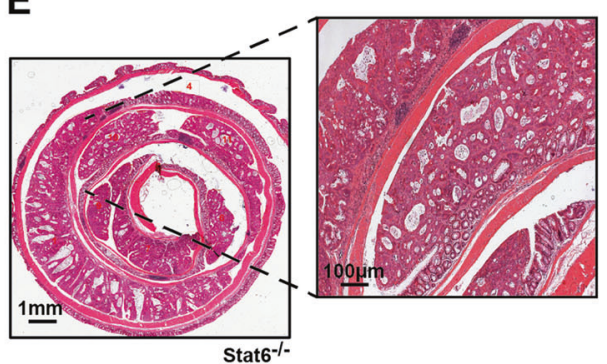

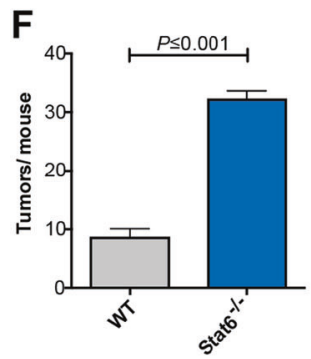

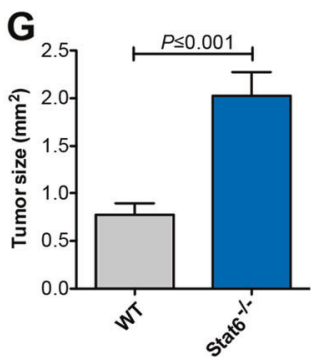

Fig. 1 Stat6 suppress colitis-associated carcinogenesis a-g. a-g Colitis-associated carcinogenesis (CAC) model performed with WT and Stat $^{-1-}$ mice ( $n=8 /$ genotype); b, c H\&E stained sections of colons and quantification of histological damage after chronic colitis in WT and Stat $6^{-I-}$ mice (WT $n=5 ;$ Stat $^{-l-} n=7$ ); d, e Representative

(Fig. 2k-m). Consequently, Stat3-deficiency in IEC reduced tumor growth in Stat6 $^{-1-}$ mice (Fig. 2n).

\section{Stat6 expression in IEC prevents inflammation- associated tumorigenesis}

To determine whether the increased sensitivity to DSSinduced inflammation and elevated tumor load in Stat $^{-1-}$ mice was dependent on loss of Stat6 in hematopoietic cells or another cell compartment, we performed adoptive transfer experiments. To this end, we transplanted Stat $6^{-/-}$ bone marrow into lethally irradiated WT mice $\left(\right.$ Stat $^{-1-} \mathrm{BM}$ $>$ WT) or conversely transferred WT bone marrow into Stat6 $^{-1-}$ recipients (WT BM $>$ Stat $^{-/-}$) (Fig. 3a). Six weeks after transplantation when mice were successfully reconstituted (Figure Suppl. 1C), animals were challenged with AOM/DSS and tumor growth was assessed. Similarly to non-transplanted Stat6 $^{-/-}$mice, Stat6 ${ }^{-/-}$animals receiving WT bone marrow were very susceptible to DSS-
H\&E stained sections of colonic tumors from WT and Stat $^{-1-}$ mice; $\mathbf{f}$, g Histological analysis and quantification of tumor incidence and tumor growth in WT and Stat6 ${ }^{-1-}$ mice at the end of the CAC model $(n=8 /$ genotype $)$. Data are mean \pm SEM

induced colitis and because of their increased weight loss and rectal bleeding mice had to be euthanized on day 54 of the model (Fig. 3b). Tumor incidence, tumor size as well as STAT3 phosphorylation was increased in Stat $^{-1-}$ mice that had received WT bone marrow (Fig. 3c-g), indicating that the lack of Stat6 expression in non-hematopoietic cells such as IEC or stromal fibroblasts was responsible for the elevated tumor load. Because Stat6 activation was only detectable in intestinal organoids but not intestinal fibroblasts (Fig. 3h), we reasoned that Stat6 expression in IEC most likely conferred tumor suppression in this model.

\section{Stat6 loss reduces alkylation-induced DNA damage, due to changes in the expression of chromatin- remodeling proteins}

The extent of initial epithelial cell death during the AOM/ DSS model substantially determines the outcome of DSSinduced colitis since increased colonic epithelial cell loss 
A

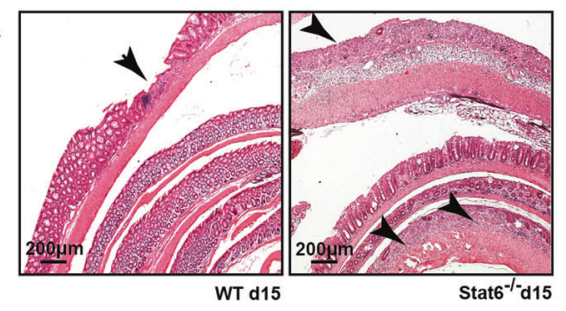

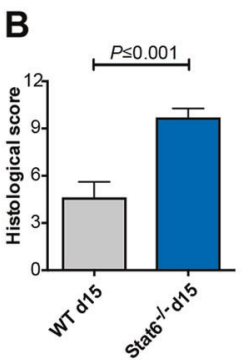

C

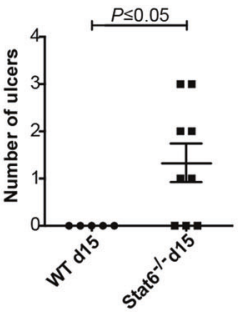

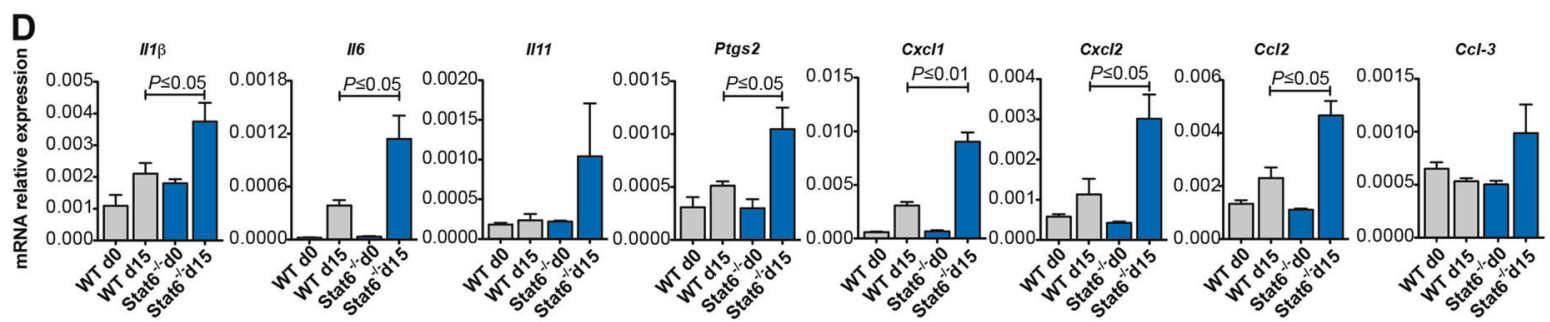

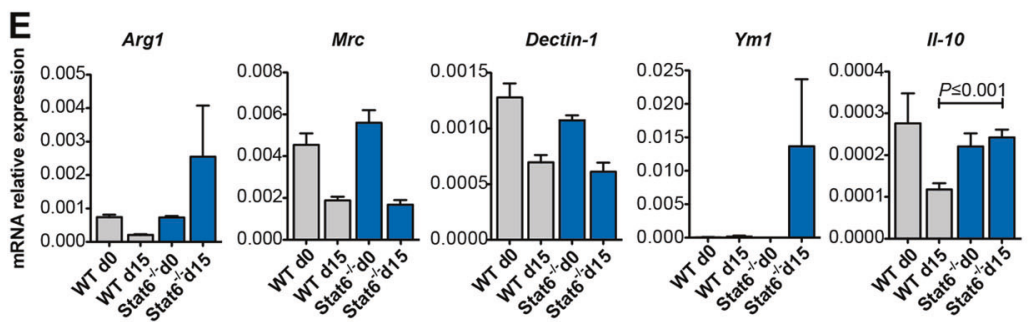

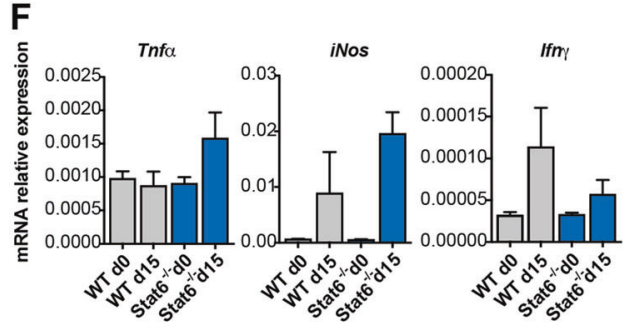

I
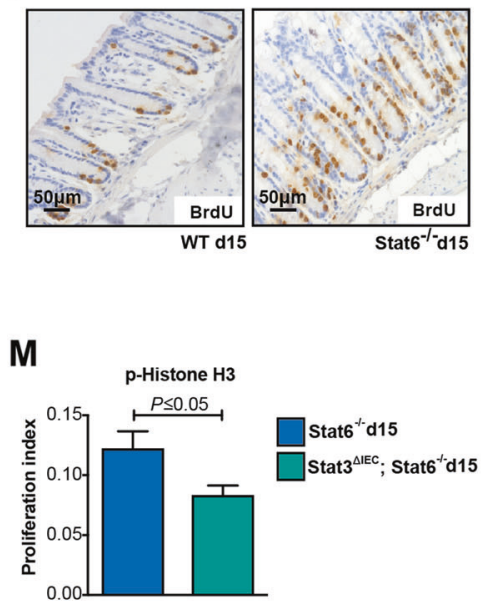

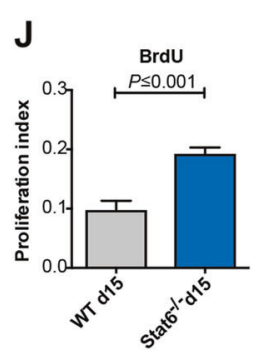

$\mathbf{N}$

G

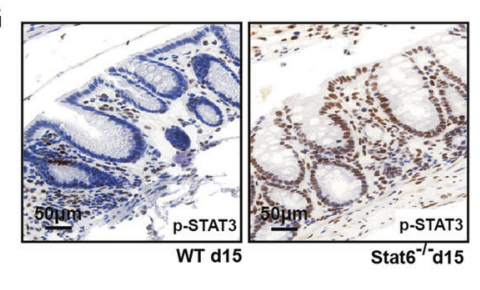

K
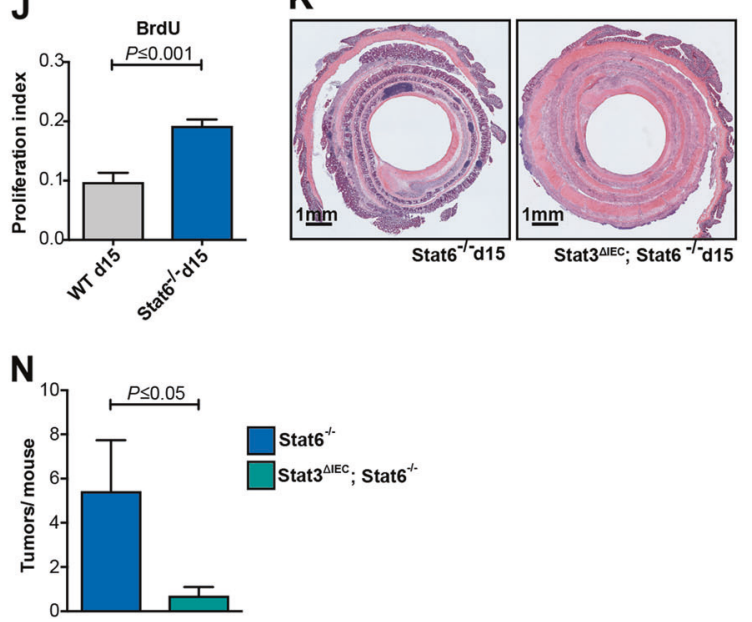

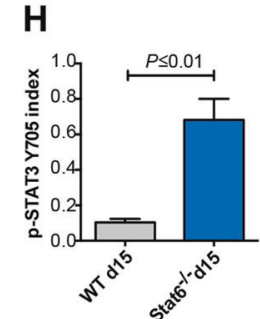

L

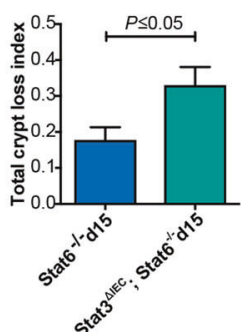

causes a more pronounced barrier defect and subsequently a stronger inflammatory response [19, 22, 23]. Considering the results of the adoptive transfer experiments that pointed to a role of Stat6 in epithelial cells in the AOM/DSS model, we hypothesized that Stat6 deletion would affect cell death of colonic epithelia. AOM administration causes DNA 
Fig. 2 Stat6 deletion increases DSS-induced colitis severity $\mathbf{a}-\mathbf{n}$. $\mathbf{a}-\mathbf{m}$ The mice were subjected to one i.p. injection of AOM (day 0) and exposed to $2 \%$ DSS in the drink water for five days (days 5-10), being killed after 5 days of recovery in normal water (day 15). a Representative H\&E stained sections of colons from WT and Stat6 ${ }^{-1-}$ mice (H\&E); b, c Histological scoring of mucosal damage, inflammation and ulceration in WT and Stat $^{-1-}$ mice at day 15 of the AOM/DSS model (WT $n=5 ;$ Stat6 $^{-1-} n=9$ ); $\mathbf{d}-\mathbf{f}$ RT-PCR, expression analysis of inflammation-related and M2/M1 genes in the mucosa of unchallenged (day 0) and AOM/DSS-treated mice at day 15 (WT d0/Stat $6^{-1-}$ d0 $n=3$; WT d15/Stat ${ }^{-1-} \mathrm{d} 15 n=5$ ); $\mathbf{g}, \mathbf{h}$ Immunohistochemical analysis and quantification of p-STAT3 Y705 performed with colonic sections of WT and Stat $^{-l-}$ mice (WT d $15 n=5$; Stat $^{-l-}$ d15 $n=$ 4); i, j Immunohistochemical analysis and quantification for BrdU incorporation in WT and Stat6 ${ }^{-1-}$ mice (WT d15 $n=5 ;$ Stat $^{-1-} \mathrm{d} 15$ $n=9$ ); $\mathbf{k}$ Representative H\&E stained sections from colons of Stat $6^{-1-}$ and Stat $3^{\text {IIEC}} ;$ Stat $^{-1-}$ double knockout mice at day 15 of AOM/DSS model; I Quantification of areas of total crypt loss in Stat6 $^{-1-}$ and Stat $^{\text {LIEC }}$; Stat $^{-l-}$ double knockout at day 15 of AOM/DSS model $\left(\right.$ Stat6 $^{-l-} \mathrm{d} 15 n=16$; Stat $\left.^{\text {IIEC }}{ }^{\text {Stat }}{ }^{-1-} \mathrm{d} 15 n=15\right) ; \mathbf{m}$ Index of pHistone H3 expressing IEC in Stat $^{-1-}$ and Stat ${ }^{\text {IIEC}}{ }^{\text {Stat }}{ }^{-1-}$ double knockout mice at day 15 of the AOM/DSS model $\left(\right.$ Stat $^{-1-} \mathrm{d} 15 n=5$; Stat $^{\mathrm{LIEC}} ;$ Stat $\left.^{-1-} \mathrm{d} 15 n=10\right) ; \mathbf{n}$ Tumor incidence in Stat $^{-1-}(n=7)$ and Stat $^{\mathrm{LIEC}} ;$ Stat $^{-1-}$ mice $(n=10)$ at the end of the CAC model. Animals were exposed to reduced DSS concentration during the CAC cycles to prevent mortality ( $0.5 \%, 0.8$ and $1 \%$ DSS, respectively). Data are mean \pm SEM

alkylation and formation of O6-methylguanine. This triggers activation of DNA damage response pathways culminating in DNA repair as well as apoptosis [24, 25]. Indeed, the number of apoptotic IEC was markedly enhanced in Stat6 $^{-1-}$ mice within $8 \mathrm{~h}$ after AOM administration (Fig. $4 \mathrm{a}-\mathrm{c})$. Moreover, also in response to DSS Stat6-deficient epithelia expressed more cleaved caspase 3 positive cells on day 8 of the AOM/DSS model (Fig. 4d-f) supporting the notion that the increased inflammatory response observed in Stat $^{-1-}$ mice during colitis was a consequence of enhanced epithelial cell loss. To determine how Stat6 affected AOMinduced apoptosis, we first examined the phosphorylation of the histone variant $\mathrm{H} 2 \mathrm{AX}$, which comprises one of the earliest events in response to DNA damage [26]. Surprisingly, H2AX phosphorylation was reduced in AOMchallenged Stat6 ${ }^{-1-}$ IEC (Fig. 4g, h). Similarly, H2AX phosphorylation was reduced in colonic organoids challenged with the alkylating agent $N$-methyl- $N^{\prime}$-nitro- $N$ nitrosoguanidine (MNNG) (Fig. 4i), confirming a cell autonomous effect. Yet, in agreement with a reduced DNA damage response in Stat $^{-1-}$ cells ATM and CHK2 phosphorylation was diminished, which was accordingly associated with impaired p53 phosphorylation (Fig. 4j-1). This suggested that the increased cell death in Stat $^{-1-}$ mice was not dependent on p53. Moreover, no difference in expression of BCL-XL, BCL-2 or BAX could be detected between the genotypes in response to the AOM challenge. Instead, we observed enhanced IRE1- $\alpha$, p-PERK, p-EIF2A, and CHOP expression in Stat $^{-1-}$ IEC indicating an enhanced unfolded protein response (UPR), which could account for apoptosis induction (Fig. 4j) [27, 28].

Modifications in heterochromatin structure can affect the DNA-damage response [29-33] and changes in the expression of chromatin-remodeling proteins, such as the heterochromatin protein 1 family members $(\mathrm{HP} 1 \alpha / \beta / \gamma)$ may increase sensitivity to DNA damage [34], while STATs can interfere with the expression of HP1 family members [35-37]. Intriguingly, we detected increased levels of HP1 $\gamma$ and HP1 $\beta$ in the lysates of unchallenged IEC from Stat6 $^{-1-}$ mice as well as in untreated Stat6deficient organoids (Fig. 5a, and Figure Supp. 2A, B). Consequently, karyotyping analysis revealed that Stat6deficient cells exhibited increased chromosome condensation when compared with their WT controls (Fig. $5 \mathrm{~b}, \mathrm{c})$. In line with impaired chromatin accessibility due to chromosome condensation, expression of the repressive histone mark H3K27me3 was markedly elevated (Fig. 5d). To further validate these results, we pretreated WT and Stat $^{-1-}$ mice for five consecutive days with valproate (valproic acid, $200 \mathrm{mg} / \mathrm{kg}$, daily), a well-known histone deacetylase (HDAC) inhibitor that leads also to chromatin decondensation [38, 39], and evaluated its effect on DNA damage response and IEC apoptosis upon the AOM challenge. Notably, valproate did not only normalize histone H2AX phosphorylation in Stat6-deficient IEC comparable to WT levels (Fig. 5e), but also increased ATM and CHK2 phosphorylation (Fig. 5f-g). Moreover, valproic acid decreased CHOP expression and prevented the enhanced IEC apoptosis observed after $8 \mathrm{~h}$ in AOMchallenged Stat6 ${ }^{-1-}$ mice (Fig. 5f, h).

Collectively, these results suggested that increased heterochromatin stability and higher chromatin compaction were responsible for the impaired DNA damage response and increased apoptosis in Stat6 $^{-1-}$ IEC.

\section{IL-4Ra in IEC is not involved in Stat6 activation during DNA damage}

To examine whether the Stat6-dependent effects on DNA damage were controlled by IL-4 receptor engagement in IEC, we generated $I l-4 r \alpha^{\Delta \mathrm{IEC}}$ mice and examined their sensitivity to AOM injection as well as tumor incidence in the AOM/DSS model. In contrast to Stat6 $^{-1-}$ mice, IECrestricted loss of IL-4R $\alpha$ did not reduce $\mathrm{H} 2 \mathrm{AX}$ phosphorylation or affected mutagen-induced cell death after AOM injection (Fig. 6a-c). Similarly, tumor incidence was not affected in $I l-4 r \alpha^{\Delta \mathrm{IEC}}$ mice in the AOM/DSS model (Fig. 6d, e). However, tumors were significantly smaller which correlated with a reduced BrdU incorporation and reduced Stat3 activation in tumor epithelia (Fig. 6d, f-j). Thus, Stat6 controls the DNA damage response independently of IL$4 \mathrm{R} \alpha$ dependent signaling in IEC. 
A

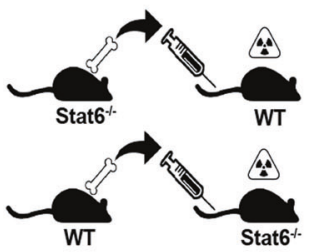

C
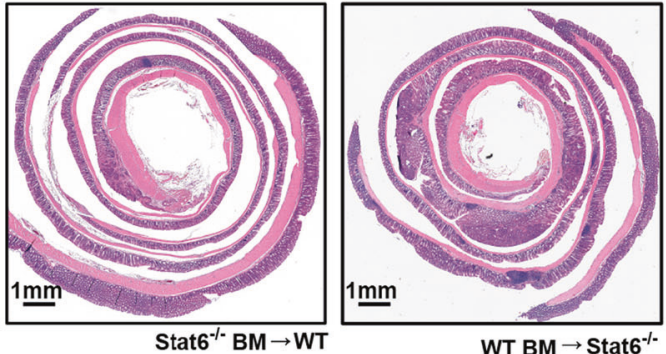

D
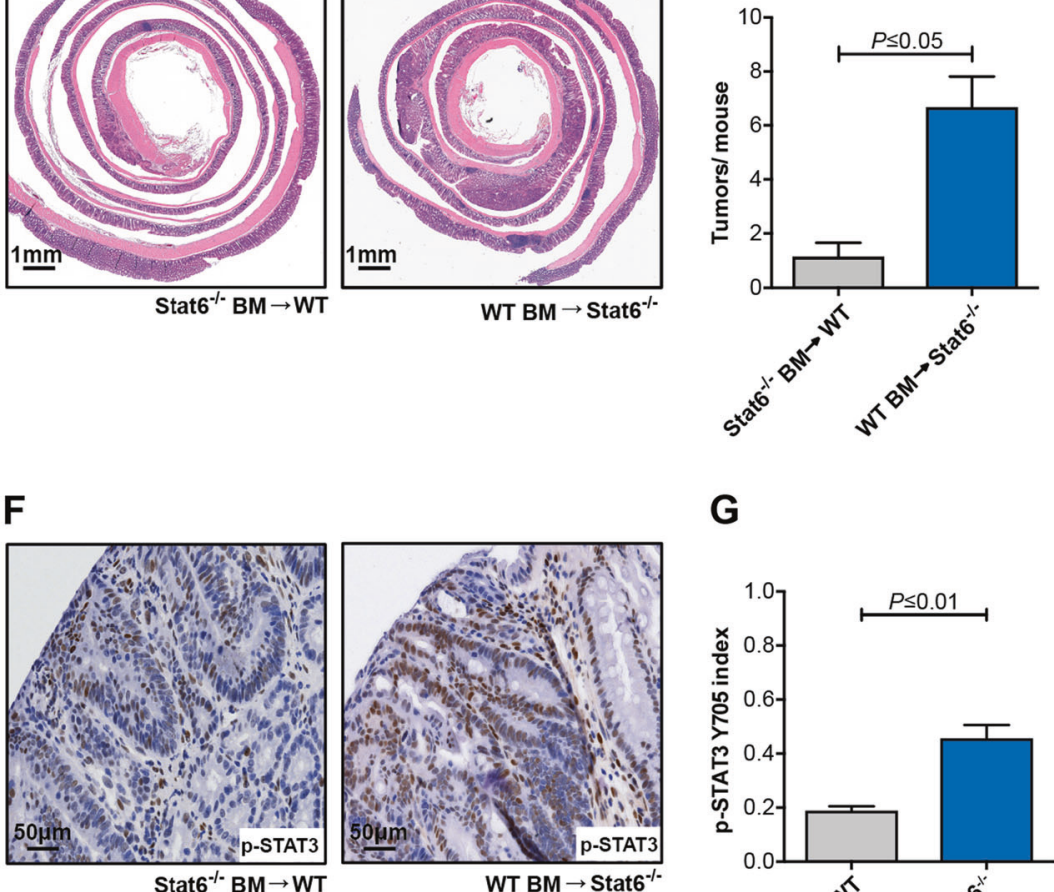

B

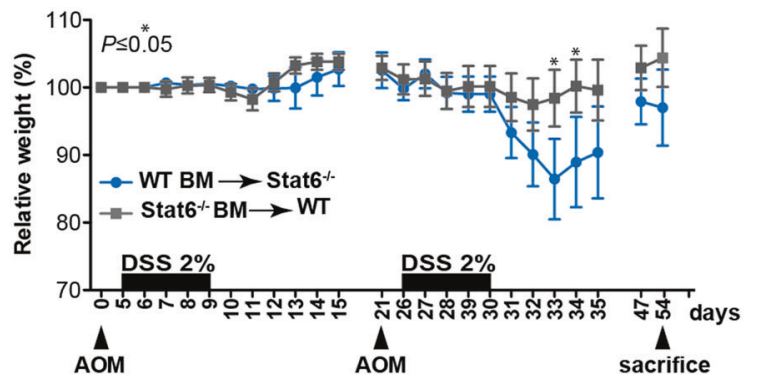

G

WT BM $\rightarrow$ Stat $6^{-1-}$

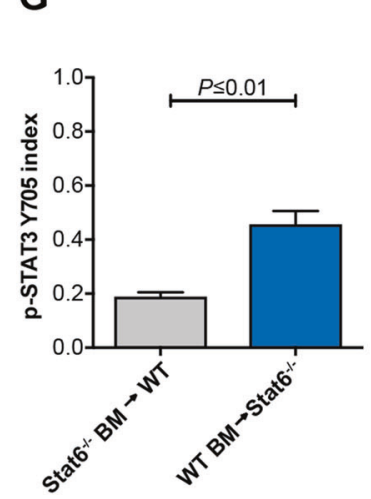

E

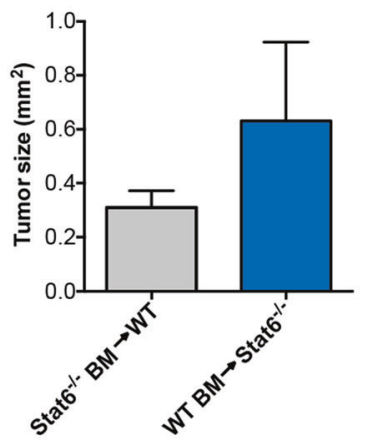

H

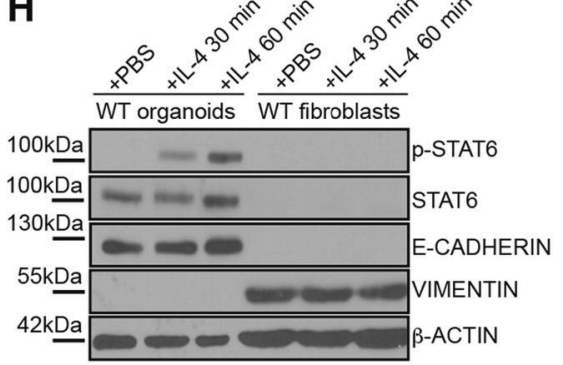

Fig. 3 Stat6 expression in intestinal epithelial cells prevents inflammation-associated carcinogenesis $\mathbf{a}-\mathbf{h}$. a Stat $^{-1-} \mathrm{BM}>\mathrm{WT}$ or WT $\mathrm{BM}>$ Stat $^{-1-}$ reconstituted mice were challenged with the CAC model; b Weight changes of transplanted mice during AOM/DSS model; c Representative H\&E stained sections of Stat $^{-1-}$ BM $>$ WT and WT BM $>$ Stat $^{-1-}$ mice colonic tumors; d, e Tumor incidence and tumor size in Stat $^{-1-} \mathrm{BM}>\mathrm{WT}$ and WT BM $>$ Stat $^{-1-}$ mice at the end of the CAC model $\left(\right.$ Stat $^{-1-} \mathrm{BM}>\mathrm{WT} n=7$; WT BM $>$ Stat6

\section{Stat6 promotes sporadic inflammation-independent carcinogenesis}

Our data suggested that due to increased initial IEC death a more severe inflammatory response during the DSS-induced colitis led to an upregulation of Stat3-activating cytokines, which promoted tumor growth and compensated the loss of initiated epithelial cells. Therefore, we hypothesized that Stat $^{-1-}$ mice should be protected from AOM-induced $\left.{ }^{-{ }^{-}} n=6\right) ; \mathbf{f}, \mathbf{g}$ Immunohistochemical analysis and quantification of $\mathrm{p}-$ STAT3 Y705 in tumors from Stat $^{-1}{ }^{-}$BM $>$WT and WT BM $>$Stat6 ${ }_{-1}$ mice $(n=3$ /genotype); $\mathbf{h}$ Immunoblot analysis of p-STAT6 Y641 from WT colon organoids and fibroblast lysates stimulated with recombinant mouse IL-4 for 30 and $60 \mathrm{~min}$. E-cadherin and Vimentin antibodies were used to ensure the respective epithelial and mesenchymal origin of the samples. $\beta$-actin as loading control. Data are mean \pm SEM

tumorigenesis when this model was done in the absence of DSS-induced colitis. Indeed, repetitive AOM-injections (six weekly i.p. injections) represent a valuable model for sporadic tumorigenesis, which leads to formation of colonic tumors within 20 weeks (Fig. 7a). As expected, increased apoptotic cell death in response to AOM led to a reduction in tumor number in this model (Figs. $4 \mathrm{c}$ and $7 \mathrm{~b}, \mathrm{c}$ ). In line with unchanged Stat3 activation in tumor epithelia, tumor sizes and proliferation rates determined by BrdU 
A
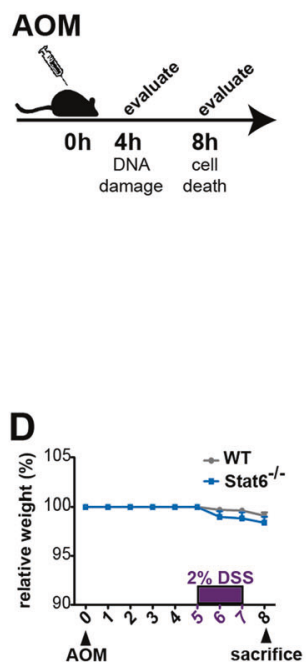

G

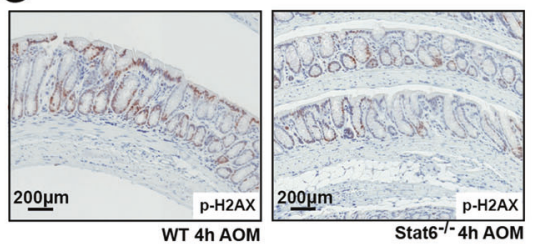

E

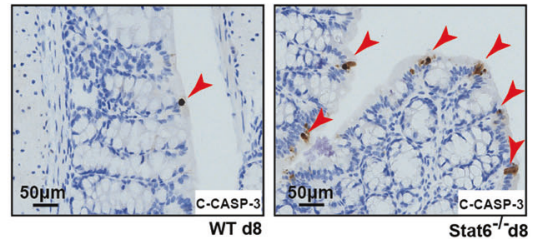

$\mathrm{H}_{0.25}$

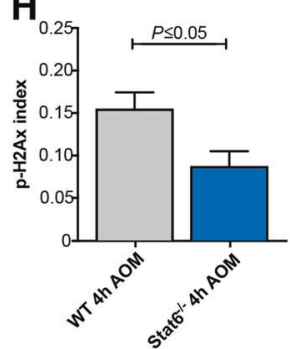

C

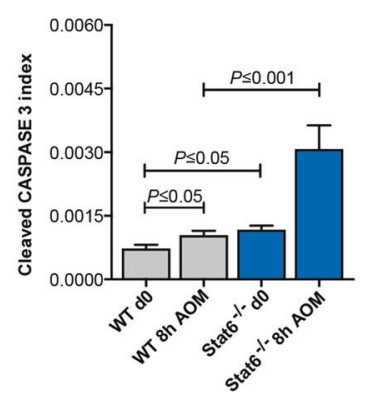

$\mathbf{F}$

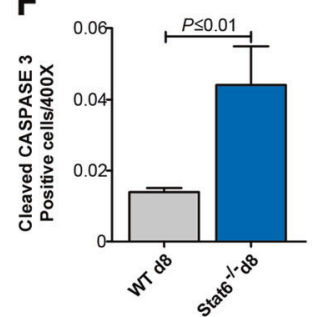

I
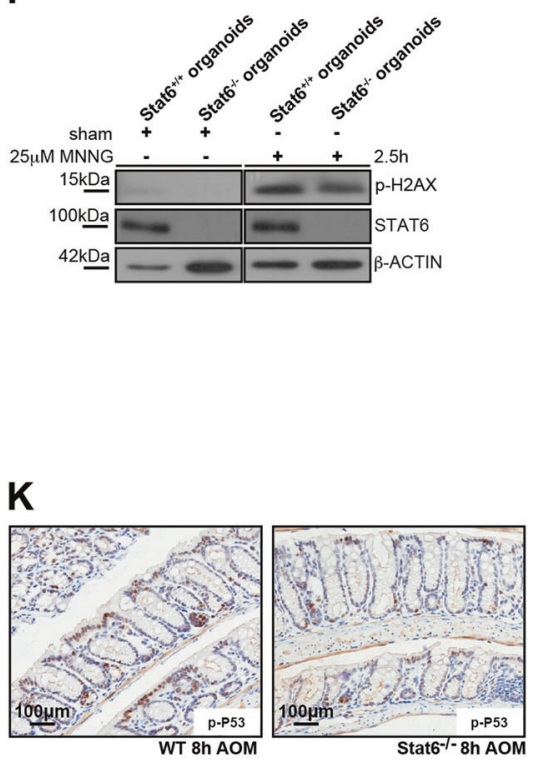

J
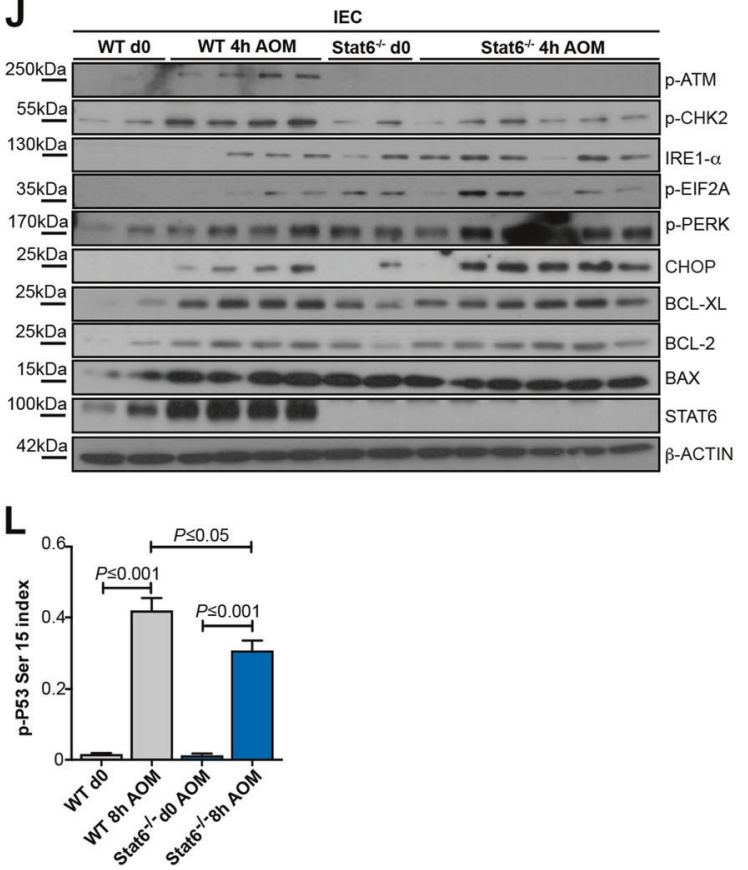

incorporation were comparable to control mice (Fig. 7d-g). Interestingly, also $\mathrm{H} 2 \mathrm{AX}$ phosphorylation was not decreased in established Stat6-deficient tumors (Fig. 7h).
Collectively, these data clearly support a tumor promoting function of Stat6 in IECs during early sporadic colorectal carcinogenesis. 
Fig. 4 Stat6 regulates IEC death and alkylating-inducing DNA damage a-l. a-c Immunohistochemical staining and index of cleaved CASPASE 3 expression in unchallenged (d0) and AOM-treated $(8 \mathrm{~h})$ WT and Stat6 ${ }^{-1-}$ IEC (WT d0 $n=6$; Stat $^{-1-}$ d0 $n=3$; WT $8 \mathrm{~h} \mathrm{AOM}$ $n=8 ;$ Stat $^{-l-} 8 \mathrm{~h}$ AOM $n=6$ ); d-f Immunohistochemical staining and index of cleaved CASPASE 3 expression in IEC on day 8 (d 8) of the CAC model ( $n=5 /$ genotype); $\mathbf{g}, \mathbf{h}$ Immunohistochemical staining and index of $\mathrm{p}-\mathrm{H} 2 \mathrm{AX}$ in AOM-treated $(4 \mathrm{~h}) \mathrm{WT}$ and Stat6 $^{-1-}$ IEC (WT $4 \mathrm{~h}$ AOM $n=7$; Stat $^{-l-} 4 \mathrm{~h}$ AOM $n=6$ ); i Immunoblot analysis of H2AX phosphorylation and STAT6 in WT $\left(\right.$ Stat6 $\left.^{+/+}\right)$and Stat6 $6^{-/-}$ colonic organoids treated $2.5 \mathrm{~h}$ with $25 \mu \mathrm{M}$ MNNG or $0.03 \%$ DMSO in PBS (sham). $\beta$-actin as loading control; $\mathbf{j}$ Immunoblot analysis of $\mathbf{p}$ ATM, p-CHK2, IRE1-a, p-EIF2A, p-PERK, CHOP, BCL-XL, BCL-2, BAX, and STAT6 performed with IEC lysates from unchallenged (d0) or AOM-treated (4h) mice. $\beta$-actin as loading control; $\mathbf{k}$, I Immunohistochemical staining and index of p-P53 S15 expression in unchallenged (d0) and AOM-treated ( $8 \mathrm{~h})$ WT and Stat ${ }^{-1-}$ IEC (WT d0 $n=$ 6; Stat6 $^{-1-}$ d0 $n=3$; WT 8 h AOM $n=9$; Stat6 $^{-1-} 8$ h AOM $n=6$ ). Data are mean \pm SEM

\section{Discussion}

A considerable amount of data endorses the concept that Stat6 is critical to mediate transcriptional activation upon IL-4 and IL-13 stimulation, emphasizing the important canonical IL-4/IL-13 dependent functions of Stat6 in immune cells [11-13]. However, Stat6 direct functions on intestinal epithelial cells during homeostasis and colorectal carcinogenesis remained elusive. Here, using genetically modified mice and different experimental models of colorectal carcinogenesis we show that Stat6 unexpectedly exerts important direct IL-4R $\alpha$ independent cell-intrinsic functions in IEC.

Intestinal homeostasis is maintained due to the close interaction of many different factors, including gut microbiota composition, immune system activation and intestinal epithelial cell differentiation and survival. The balance between these factors is crucial to the host, and its disruption can lead to the development of a number of diseases. The finding that Stat6 loss can directly regulate IEC death in vivo, and therefore affect colitis severity and colorectal carcinogenesis is important to clarify its function during these two different conditions. During DSS-induced colitis Stat6 loss triggers enhanced IEC apoptosis, causing intense tissue damage and massive inflammatory response, with secretion of many pro-inflammatory chemokines and cytokines that later activate intestinal epithelial cell-intrinsic survival mechanisms. The enhanced expression of Il- 6 and Il-11, followed by strong Stat 3 activation and enhanced $\mathrm{BrdU}$ incorporation found in the mucosa of $\mathrm{Stat}^{-1-}$ mice at day 15 of the CAC model support this notion. Stat3overexpressing enterocytes unequivocally disturb the regeneration of the damaged epithelium, inducing aberrant IEC proliferation and later tumorigenesis [22]. The increased tumorigenesis found in these mice at the end of the CAC model along with the results obtained with
Stat ${ }^{\text {SIEC}} ;$ Stat $^{-1-}$ mice support the concept that tumor formation and growth in Stat6-deficient mice is promoted by Stat 3 activation in enterocytes at the earlier DSS-induced colitis. Unexpectedly, gene expression analysis of the colonic mucosa of Stat $^{-/-}$mice during colitis as well as of tumor samples collected at the end of the CAC model did not detect significant changes in the expression of alternative and classical activation genes, suggesting that these markers might not play a critical role in this experimental model (Fig. 2e, f and data not shown). Recently, LeonCabrera et al., also reported that Stat6-deficient mice exhibit increased IEC cell death at the early stages of CAC [40]. Yet, in this study Stat $^{-/-}$mice developed a reduced inflammatory response and a lower number of colonic tumors, possibly due to a different experimental set up (i.e. lack of cohoused control mice or no exchange of bedding) causing changes in the intestinal microbiome. While our finding that Stat $^{-/-}$mice are more susceptible to mucosal damage is in agreement with other previous reports [41, 42], our results markedly differ. Previous studies suggested that Stat $6^{-1-}$ mice enhanced susceptibility mucosal damage is due to changes in the phenotype of myeloid cells, especially macrophages. However, in these reports the immediate effects of Stat6 deletion on intestinal epithelial cell death and survival had not been examined.

By now it is widely accepted that a pro-inflammatory intestinal microenvironment predisposes to the activation of oncogenes, which later trigger the expression of tumorpromoting molecules driving neoplastic transformation [3, $25,43-50]$. We had previously demonstrated that upon genotoxic stress, the early death of the intestinal initiated epithelium leads to higher protection against tumor formation $[22,25]$. This effect is based on the elimination of genetically damaged epithelial cells, which when allowed proliferating would acquire and accumulate additional mutations that would provide them with cell-autonomous growth advantages. As Stat6-deficient IEC were more susceptible to undergo apoptosis upon AOM challenge it was expected that during sporadic colitis-independent carcinogenesis Stat6 $^{-1-}$ mice would exhibit reduced number of tumors. Surprisingly, we found that AOM-induced apoptosis appears to be independent of p53 activation in these mice, which was further confirmed by crossing Stat $^{-1-}$ mice to intestinal cell-specific deleted Tp53 mice $\left(T p 53^{\Delta \mathrm{IEC}}\right)$. The resulting animals were challenged with sporadic colitis-independent cancer model, and similarly to AOM-induced Stat $^{-1-}$ mice, Stat6 ${ }^{-1-} ;$ Tp $53^{\Delta \mathrm{IEC}}$ double mutants developed a significantly lower number of tumors (De Oliveira, unpublished observations), confirming the essential role of early carcinogen-triggered apoptosis in this model. Supporting our findings on sporadic carcinogenesis, it has been recently shown that Stat6 deletion in the $A p c^{\text {Min/ }}$ ${ }^{+}$mouse model reduced the incidence of polyps in the small 
A

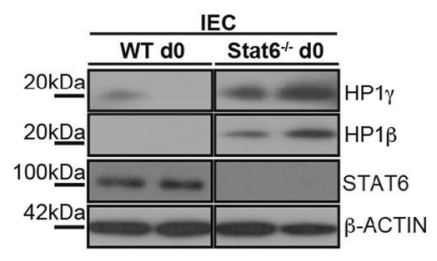

D

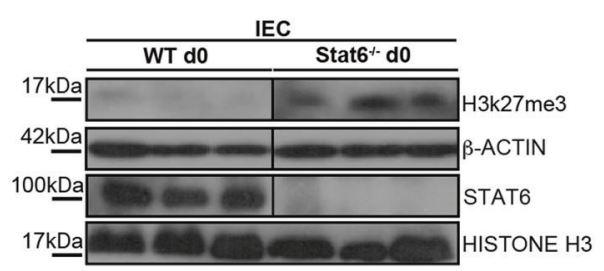

B

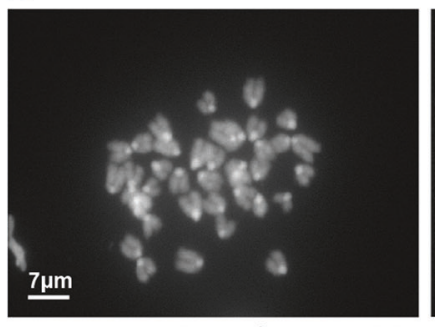

Stat $6^{+/+}$organoids

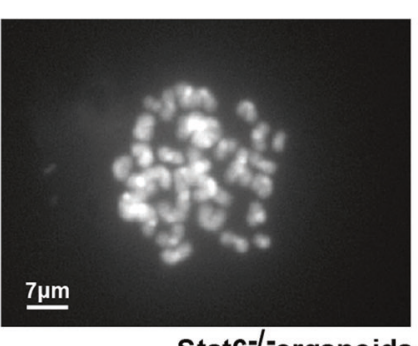

Stat6 ${ }^{-/-o r g a n o i d s ~}$
C

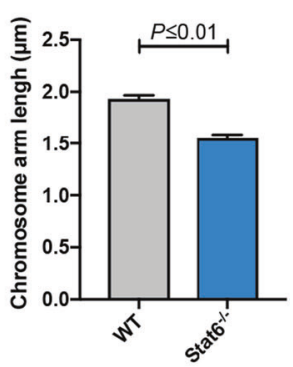

E

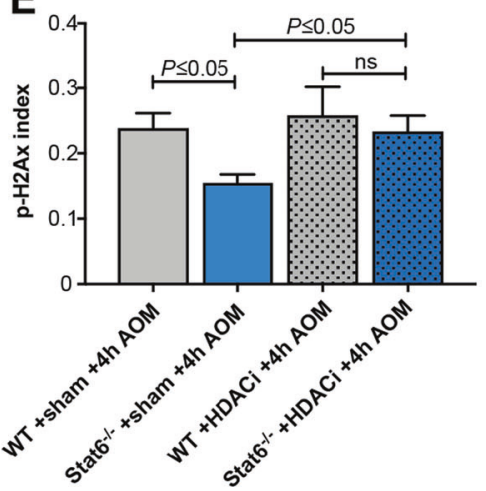

$\mathbf{F}$

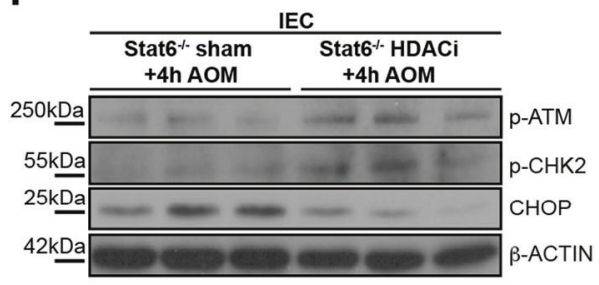

G
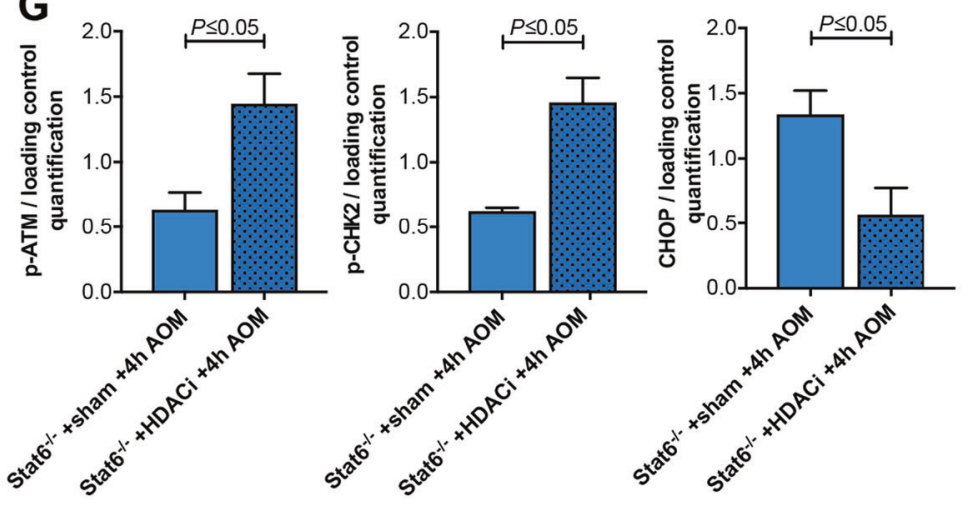

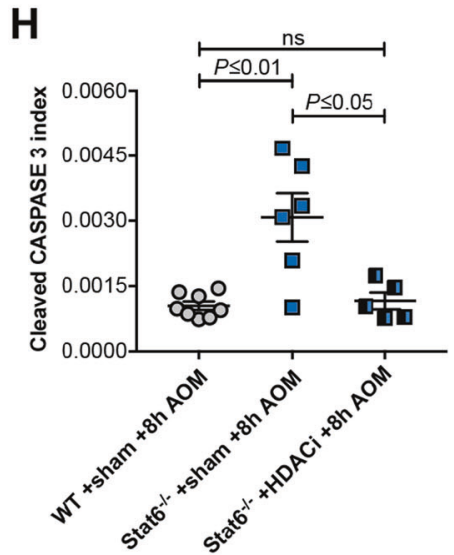

Fig. 5 Stat6 loss affects the expression of chromatin-remodeling proteins and chromatin compaction $\mathbf{a}-\mathbf{h}$. a Immunoblot analysis of HP1 $1 \gamma /$ $\beta$ in unchallenged (d0) WT and Stat6 ${ }^{--}$IEC. $\beta$-actin as loading control. b, c Karyotype analysis and chromosome arm length measurement in WT and Stat $^{-/-}$colon organoids; $\mathbf{d}$ Immunoblot analysis of H3K27me3, STAT6, and HISTONE H3 in unchallenged (d0) WT and Stat $^{-1-}$ IEC. $\beta$-actin as loading control. e p-H2AX index in AOM-treated (4 h) WT and Stat6 ${ }^{-1-}$ IEC pretreated with $\mathrm{NaCl} 0.9 \%$ (sham) or HDAC inhibitor (HDACi) for 5 days (WT or Stat6 $^{-1-}+$ sham +4 h AOM $n=3$, respectively; WT or Stat $^{-1-}+\mathrm{HDACi}+4 \mathrm{~h}$
AOM $n=4$, respectively); $\mathbf{f}, \mathbf{g}$ Immunoblot analysis and quantification of p-ATM, p-CHK2 and CHOP in Stat6 ${ }^{-1-}$ IEC from mice that had been pretreated with $\mathrm{NaCl} 0.9 \%$ (sham) or HDACi for five consecutive days. $\beta$-actin as loading control. Results were normalized to the loading control. $\mathbf{h}$ Index of cleaved CASPASE 3 expression in AOMtreated $(8 \mathrm{~h})$ WT and Stat $^{-/-}$IEC from mice that had been pretreated with $\mathrm{NaCl} 0.9 \%$ (sham) or HDACi for five consecutive days (WT+ sham +8 h AOM $n=8 ;$ Stat6 $^{-1-}+$ sham +8 h AOM $n=6 ;$ Stat $^{-1-}$ $+\mathrm{HDACi}+8 \mathrm{~h}$ AOM $n=5$ ). Data are mean \pm SEM 
A

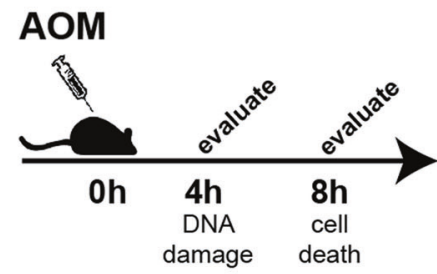

D
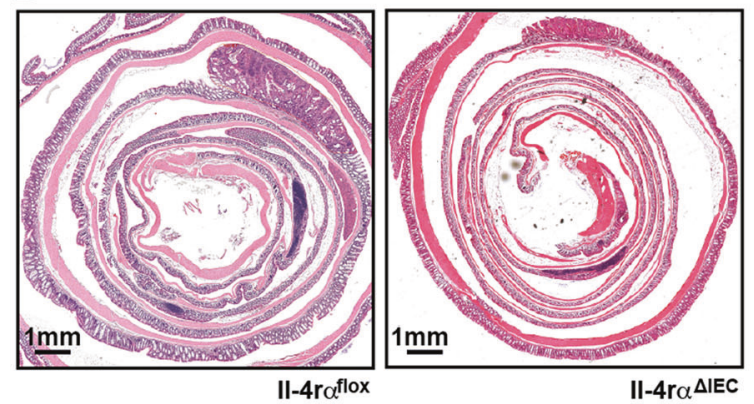

G
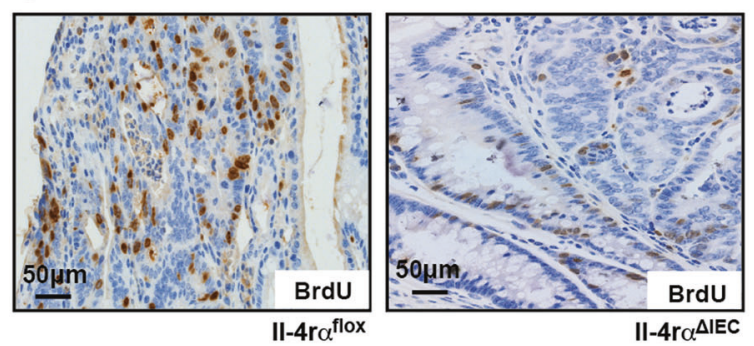

I
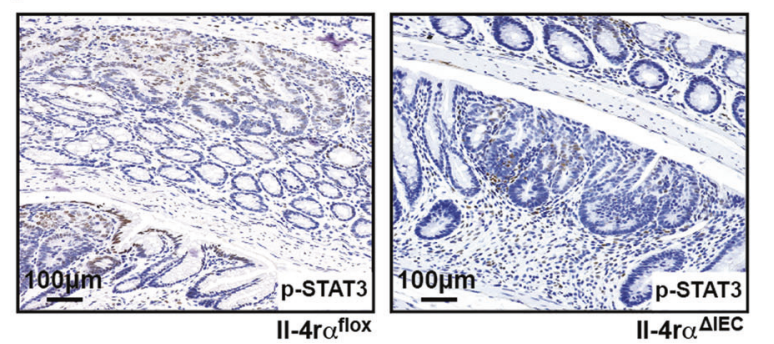

B

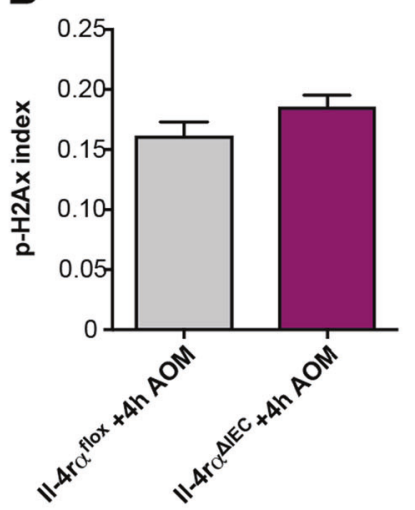

E
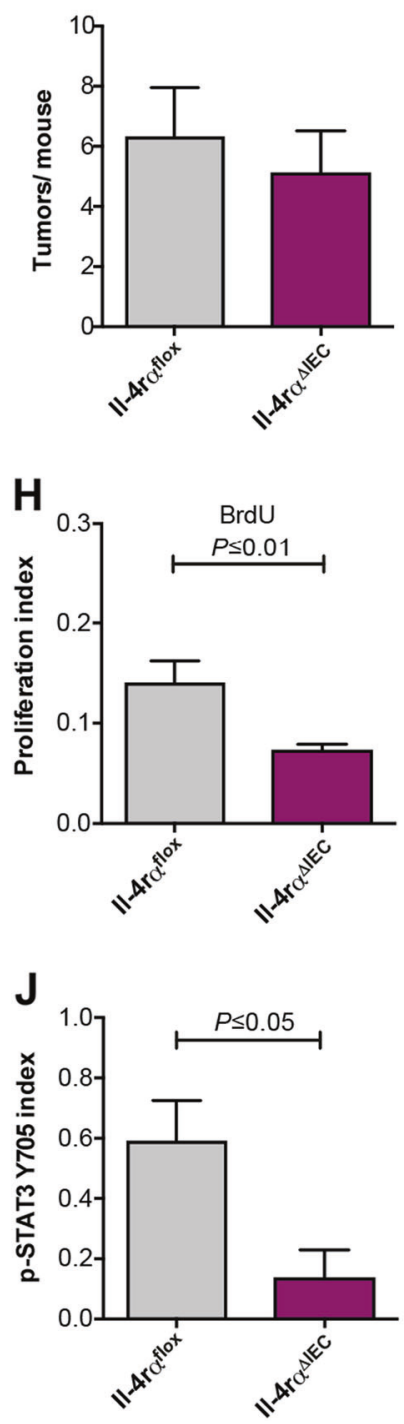

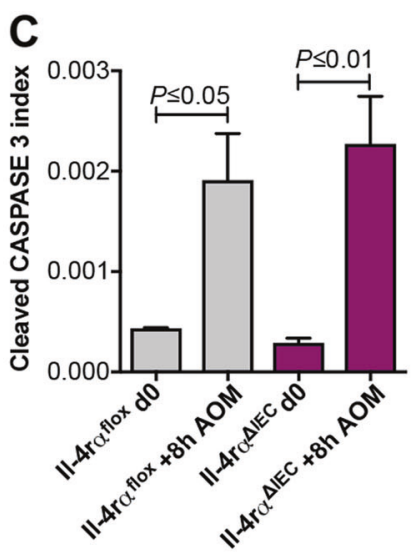

F

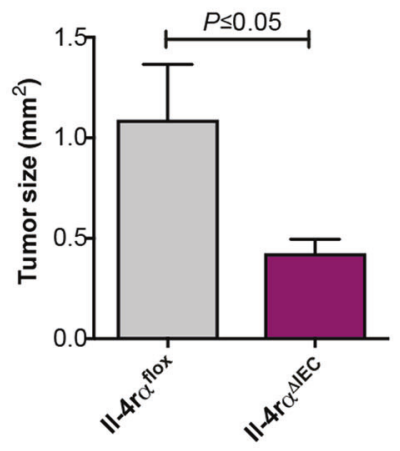


Fig. 6 IL-4R $\alpha$ is not involved in Stat6 activation during DNA damage a-j. a, b p-H2AX index in AOM-treated (4h) $\mathrm{Il}-4 r \alpha^{f l o x}(n=5)$ and $\mathrm{Il}$ $4 r \alpha^{\Delta \mathrm{IEC}}$ mice $(n=6)$; a, c Index of cleaved CASPASE 3 expressing IEC in unchallenged (d0) and AOM-treated $(8 \mathrm{~h}) \mathrm{Il}-4 \mathrm{ro}^{f l o x}$ and $\mathrm{Il}$ $4 r \alpha^{\Delta \mathrm{IEC}}$ mice $\left(I l-4 r \alpha^{f l o x} \mathrm{~d} 0 n=3 ; I l-4 r \alpha^{\Delta \mathrm{IEC}} \mathrm{d} 0 n=5 ; I l-4 r \alpha^{f l o x}+8 \mathrm{~h}\right.$ $\mathrm{AOM} n=4 ; I l-4 r \alpha^{\Delta \mathrm{IEC}}+8 \mathrm{~h}$ AOM $\left.n=4\right) ; \mathbf{d}-\mathbf{j}$ CAC model performed with $I l-4 r \alpha^{f l o x}$ and $I l-4 r \alpha^{\Delta \operatorname{IEC}}$ mice $(n=10 /$ genotype); d Representative $\mathrm{H} \& \mathrm{E}$ stained sections of colonic tumors from $\mathrm{Il}-4 \mathrm{r \alpha} \mathrm{flox}^{\text {flo }}$ and $\mathrm{Il}-4 \mathrm{r \alpha} \mathrm{L}^{\mathrm{IEC}}$ mice; e, f Tumor incidence and tumor size of $I l-4 r \alpha^{f l o x}$ and $I l-4 r \alpha^{\Delta I E C}$ mice at the end of the CAC model ( $n=10 /$ genotype); $\mathbf{g}$, h BrdU incorporation in tumors from $\mathrm{Il}-4 \mathrm{r \alpha} \alpha^{f l o x}(n=5)$ and $\mathrm{Il}-4 \mathrm{r \alpha}{ }^{\mathrm{IIEC}}(n=7)$ mice; $\mathbf{i}, \mathbf{j}$ Immunohistochemical staining and index of p-STAT3 Y705 expressing tumor epithelia in $I l-4 r \alpha^{f l o x}$ and $I l-4 r \alpha^{\Delta \mathrm{IEC}}$ mice $(n=3 /$ genotype). Data are mean \pm SEM

intestine, and that Stat6-deficient $A p c^{\mathrm{Min} /+}$ polyps exhibited increased cell death [18]. However, this effect was attributed to increased cytotoxic activity of Stat6-deficient CD8 ${ }^{+}$ T cells.

Stats, as well as Janus Kinases (Jaks), are best known by their canonical functions which upon phosphorylation mediate intracellular signals derived from cytokines to control transcriptional activation of several different target genes. However, Stats have less-well described kinaseindependent non-canonical functions [51]. Nuclear unphosphorylated STAT92E has been found to influence heterochromatin stability in Drosophila melanogaster due to its ability to associate with HP1, an important chromatinremodeling protein. In this species, STAT92E phosphorylation reduces its heterochromatin association, leading to HP1 displacement and heterochromatin destabilization [37]. Additionally, decreased levels of unphosphorylated STAT92E-thus reducing heterochromatin stabilityinduce low resistance to DNA damage during genotoxic stress conditions [31]. Although conversely to what was observed in Drosophila, the finding that Stat6-deficient enterocytes are more resistant to AOM-induced DNA damage is supported by elevated expression of HP1 proteins as well as the heterochromatin repressor mark H3K27me3 in these cells. HP1 strong expression contributes directly to the chromatin compaction, providing extra protection against chromosomal breakages [31], whereas H3K27me3 increased expression confirms its condensed repressed status [52]. HDAC inhibitor treatment of Stat6 $^{-1-}$ mice causing chromatin decondensation validated these observations. Nevertheless, the exact regulatory mechanisms underlying changes in chromatin structure and UPR in Stat6-deficient enterocytes and whether STAT6 can direct physically interact with HP1 proteins remain to be established.

To date, Stat6 function during tumorigenesis has been mostly defined in the context of IL-4/IL-13 engagement in inflammatory immune cells. Our finding that in IEC Stat6 is involved in chromatin condensation in an IL-4R $\alpha$-independent manner may also impact cytotoxic therapy and suggests that targeting IL-4/IL-13 or Stat6 might have a very different therapeutic outcome.

\section{Materials and methods}

\section{Animal experiments}

Stat6 knockout $\left(\right.$ Stat6 $^{-1-}$ ) and C57BL/6 (WT) mice were both from the Jackson Laboratory, Bar Harbor, ME. Il$4 r \alpha^{\Delta \mathrm{IEC}}$ and $S t a t 3^{\Delta \mathrm{IEC}}$ mouse strains were obtained by crossing Il-4r $\alpha$ [53] or Stat $3^{\text {flox54 }}$ to villin-cre mice [55]. Stat $^{\mathrm{AIEC}}$; Stat6 $^{-1-}$ double knockout mice were generated by further crossing $S t a t 3^{\Delta \mathrm{IEC}}$ to Stat $^{-/-}$mice. Il-4ro $\alpha^{\Delta \mathrm{IEC}}$ and $S t a t 3^{\Delta \mathrm{IEC}} ;$ Stat6 $^{-1-}$ mice were kept on a mixed background. All animals were bred and housed at the GeorgSpeyer-Haus animal facility under specific pathogen-free conditions and controlled 12-hours light/dark cycle. Gender and age-matched mice (ranging from six to 12 weeks old) were used in all experiments. To ensure a balanced microbiome between genotypes, cage beddings were mixed twice a week between genotypes, for a minimum of 2 weeks, prior to all experiments. Additionally, animals kept under long experimental periods (e.g. CAC or sporadic carcinogenesis model) had their bedding mixed weekly. Littermates were used as controls in experiments performed with the $\mathrm{Il}$ $4 r \alpha^{\Delta \mathrm{IEC}}$ and Stat $3^{\mathrm{AIEC}} ;$ Stat $^{-1-}$ mice. Food and water were provided ad libitum. Experimental colitis was induced by administrating 2\% dextran sodium sulphate (DSS) (36-50 $\mathrm{kDa}, \mathrm{MP}$ Biomedicals, CA) in drinking water for 5 days, followed by five additional days of regular drinking water. Severity of colitis was histologically evaluated as previously described [56]. The total crypt loss index was calculated measuring the length of total crypt loss areas (in $\mu \mathrm{m}$ ) and dividing it by the total length of the colonic segment. Experimental colitis-associated carcinogenesis (CAC) was performed as previously described [43] using $10 \mathrm{mg} / \mathrm{kg}$ AOM (Sigma-Aldrich, St. Louis, MO) and 2\% DSS, unless indicated otherwise. Experimental colitis-independent (sporadic) carcinogenesis was performed subjecting animals weekly, for 6 weeks, to i.p. injections of AOM $(10 \mathrm{mg} / \mathrm{kg})$. Mice were killed 20 weeks after the first AOM injection. To evaluate the acute effects of AOM, animals were sacrificed 4 or $8 \mathrm{~h}$ after AOM $(10 \mathrm{mg} / \mathrm{kg})$ injection. Adoptive transfer experiments were performed subjecting mice to a wholebody gamma-radiation of $9.5 \mathrm{~Gy}$. Bone marrow from donor mice was collected from femoral bones and cell number determined. Approximately $1 \times 10^{6}$ cells were injected into the tail vein of lethally irradiated mice. Transplanted mice were given antibiotic water $(2 \mathrm{mg} / \mathrm{ml}$ Ciprobay, Bayer, Leverkusen, $\mathrm{NW}$ ) for 14 days, followed by 14 days of regular water before being subjected to CAC. Animals were 
A

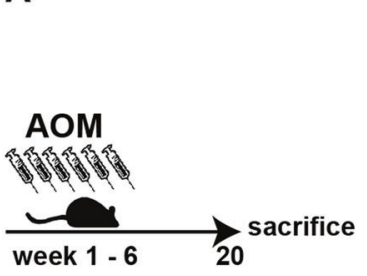

C

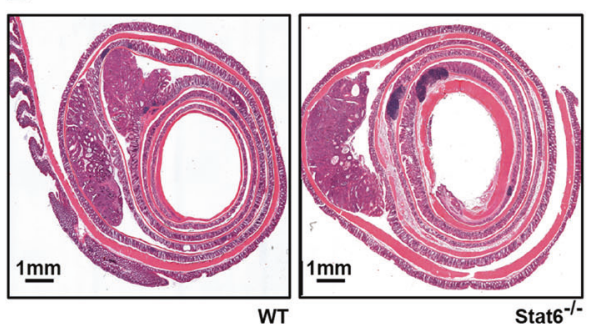

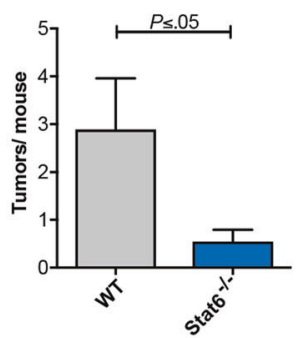

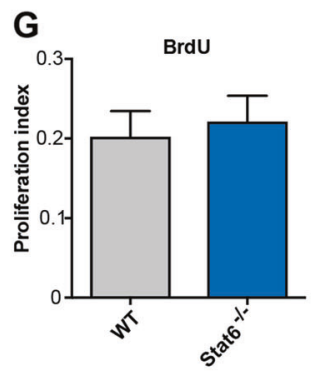

D

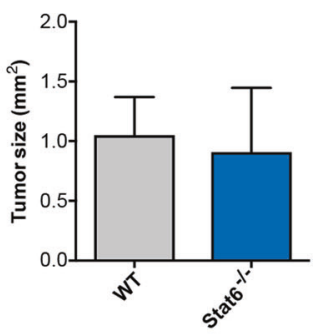

H

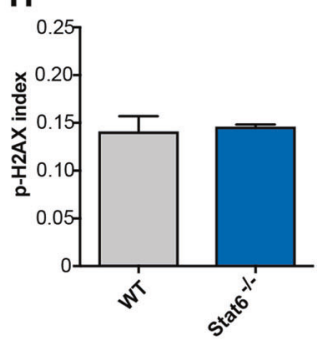

Fig. 7 Stat6 promotes sporadic inflammation-independent carcinogenesis a-h. a Colitis-independent carcinogenesis (sporadic) model performed with WT and Stat $^{-1-}$ mice; b Representative H\&E stained sections of colons from WT and Stat $^{-1-}$ mice 20 weeks after the first AOM injection; $\mathbf{c}, \mathbf{d}$ Tumor incidence and tumor size in WT and Stat6 ${ }^{-I-}$ mice (WT $n=9 ;$ Stat $^{-I-} n=11$ ); e, f Immunohistochemical

monitored and weights recorded daily during the colitisassociated experiments and three times per week in colitisindependent experiments. In all animal experiments mice with weight loss more than $20 \%$ of their initial body weight were euthanized. Evaluators were blinded to the group information and animal data analyses presented are representative of two or more experiments. All procedures were reviewed and approved by the Regierungspräsidium Darmstadt, Germany.

\section{Intestinal epithelial cell proliferation assessment}

Mice were i.p. injected with $75 \mathrm{mg} / \mathrm{kg}$ of BrdU (SigmaAldrich), $90 \mathrm{~min}$ before killing. IEC proliferation was determined by staining colonic paraffin tissues sections with anti-BrdU antibody (Serotec, Raleigh, NC). Stained sections were scanned using Aperio Scanscope XT and the proliferation index was calculated dividing the number of BrdU positive epithelial cells by the total number of epithelial cells, using Aperio Imagescope software (both, Leica Biosystems, Nussloch, BW).

\section{Immunohistochemistry}

Immunohistochemistry was performed as previously described [45]. The following antibodies were used: phospho-STAT3 Y705, phospho-Histone H2AX S139, phospho-Histone H3 S10, and cleaved Caspase 3 (all from staining and index of p-STAT3 Y705 expressing tumor epithelia in WT and Stat $^{-l-}$ mice (WT $n=5$; Stat $^{-1-} n=3$ ); g BrdU incorporation in tumors from WT and $\operatorname{Stat}^{-1-}$ mice (WT $n=4 ;$ Stat $^{-l-} n$ $=3)$; $\mathbf{h}$ Index of $\mathrm{p}-\mathrm{H} 2 \mathrm{AX}$ expressing tumor epithelia in WT $(n=5)$ and Stat $^{-l-}$ mice $(n=3)$

Cell Signaling Technology, Danvers, MA). After image acquisition using an Aperio Scanscope XT (Leica), the staining indexes were calculated dividing the number of positive epithelial cells/nuclei by the total number of epithelial cells/nuclei, using Aperio Imagescope software (Leica Biosystems). The resulted ratio is shown as index.

\section{Immunoblot analysis}

Tissues/cell lysate pellets were subjected to SDS-PAGE, transferred into $0.45 \mu \mathrm{m}$ PVDF membranes and blocked 30 minutes at room temperature with 3\% skim milk (SigmaAldrich), prior overnight incubation with the following primary antibodies: phospho-ATM S1981 and STAT6 (all from Santa Cruz Biotechnology, Dallas, TX); $\beta$-actin (Sigma-Aldrich); Vimentin, p-STAT6 Y641, Histone H3, HP1 $\gamma$, and H3K27me3 (all from Abcam, Cambridge, UK); BAX, IRE1- $\alpha$, phospho-EIF2A, phospho-CHK2 T387, CHOP, phospho-STAT3 Y705, and phospho-Histone H2AX S139 (all from Cell Signaling Technology); HP1 $\beta$ (Thermo Fischer Scientific, Waltham, MA); STAT3, BCL2, BCL-XL, and E-cadherin (BD Biosciences, Franklin Lakes, NJ); phospho-PERK (US Biologicals, Salem, MA). After $30 \mathrm{~min}$ incubation with their respectively HRPconjugated secondary antibodies (GE healthcare, Chicago, IL) membranes were developed using the SuperSignal West Pico Chemoluminescence Substrate (Thermo Fischer 
Scientific). Western blots were quantified using ImageJ $1.43 \mathrm{u}$ Software (National Institutes of Health, Bethesda, Maryland, USA. https://imagej.nih.gov/ij/, 1997-2016).

\section{Intestinal organoids}

Colonic mouse organoids were isolated and kept as previously described [56]. Organoids at passage 2-4 were used for experiments.

\section{Intestinal epithelial cell isolation}

Colons were flushed with ice-cold PBS, cut into small pieces and incubated in $10 \mathrm{ml}$ of pre-warmed $\left(37^{\circ} \mathrm{C}\right) \mathrm{HBSS}$ medium supplemented with $5 \mathrm{mM}$ EDTA (Carl Roth, Karlsruhe, BW) and $2 \mathrm{mM}$ DTT (Sigma-Aldrich). Samples were shook $(80 \mathrm{rpm})$ for $10 \mathrm{~min}$ at $37^{\circ} \mathrm{C}$. Next, the tissue was vortexed for $30 \mathrm{~s}$ and put to rest on ice for more $30 \mathrm{~s}$ to allow the lamina propria to precipitate. The supernatant was transferred to a new $50 \mathrm{ml}$ conic tube passing through a $70 \mu \mathrm{m}$ mash and further centrifuged for $5 \mathrm{~min}$ at $500 \times g, 4^{\circ}$ C. The cell pellet resuspended with $3 \mathrm{ml}$ of ice-cold PBS and divided into $1.5 \mathrm{ml}$ Eppendorf tubes. These were further centrifuged for $5 \mathrm{~min}$ at $2000 \mathrm{rpm}, 4{ }^{\circ} \mathrm{C}$, and the pelleted IEC immediately frozen in liquid nitrogen. Samples were stored at $-80{ }^{\circ} \mathrm{C}$ until use.

\section{Karyotype analysis}

The karyotyping protocol was kindly provided by Dr. Meritxell Huch (Wellcome Trust/Cancer Research UK, Cambridge, UK). Colon organoid cultures from WT (Stat6 ${ }^{+/+}$) and Stat $6^{-/-}$mice were incubated $24 \mathrm{~h}$ with $0.05 \mu \mathrm{g} / \mathrm{ml}$ Colcemid (GIBCO, Calrsbad, CA) in complete ERN medium. Organoids were dissociated into single cells using TrypLE Express (Thermo Fischer Scientific). Single-cells was resuspended in $1 \mathrm{ml} 0.075 \mathrm{M} \mathrm{KCl}$, and incubated for $10 \mathrm{~min}$ at $37^{\circ} \mathrm{C}$. Next, $1 \mathrm{ml}$ of $\mathrm{MeOH}: \mathrm{CH}_{3} \mathrm{OOH}$ solution (3:1) was added and cells centrifuged for $5 \mathrm{~min}, 1500 \mathrm{rpm}$, RT. Supernatant was removed, cells were again resuspended in $1 \mathrm{ml}$ of $\mathrm{MeOH}: \mathrm{CH}_{3} \mathrm{OH}$ solution (3:1) and incubated for $20 \mathrm{~min}$ at RT. After incubation, cells were centrifuged for $5 \mathrm{~min}, 1500 \mathrm{rpm}$ at RT and stored at $-20{ }^{\circ} \mathrm{C}$ overnight. Next day, $850 \mu \mathrm{l}$ of $\mathrm{MeOH}: \mathrm{CH}_{3} \mathrm{OOH}$ solution was removed, and cells were resuspended in the remaining volume. The cell suspension was then placed drop-wise on glass slides (SuperFrost Plus, Thermo Fischer Scientific) from a height of $\sim 50 \mathrm{~cm}$, and allowed to air-dry. Finally, slides were covered with ProLong Gold Antifade Mountant with DAPI (Thermo Fischer Scientific) and glass coverslips. Visualization and analysis of mitotic chromosomes compaction was performed measuring the Euclidean distance (in $\mu \mathrm{m})$ from the centromere to the end of the chromosome arm using Zeiss Imager.M2 microscope and AxionVision SE Rel. 4.9.1 software (Zeiss, Oberkochen Germany).

\section{RNA analysis}

RNA analysis was performed as previously described and quantified by real-time PCR [56]. Primer sequences are available on request.

\section{Statistical analysis}

Data are presented as mean \pm SEM. Statistical analysis was performed with Prism7 software (GraphPad Software Inc., La Jolla, CA) using two-tailed Student's t-test, MannWhitney test or ANOVA followed by Bonferroni post hoc test. $P<0.05$ was considered statistically significant.

Acknowledgements We thank Christin Danneil, Hana Kunkel, Preeti Gupta, Kathleen Mohs, and Eva Rudolf for technical assistance as well as Petra Dinse at the Histology Core Facility at the Georg-Speyer-Haus for excellent technical support and all members of the Greten lab for insightful discussion. We also thank Birgitta Michels for help with karyotype analysis. This work was supported in part by the LOEWE Center for Cell and Gene Therapy Frankfurt (CGT, III L 4-518/ 17.004) and institutional funds from the Georg-Speyer-Haus, as well as grants from the Deutsche Forschungsgemeinschaft (Gr1916/5-1 and FOR2438: Gr1916/11-1; SFB 815, 1177 and 1292) to F.R.G..

\section{Compliance with ethical standards}

Conflict of interest The authors declare that they have no conflict of interest

Open Access This article is licensed under a Creative Commons Attribution 4.0 International License, which permits use, sharing, adaptation, distribution and reproduction in any medium or format, as long as you give appropriate credit to the original author(s) and the source, provide a link to the Creative Commons license, and indicate if changes were made. The images or other third party material in this article are included in the article's Creative Commons license, unless indicated otherwise in a credit line to the material. If material is not included in the article's Creative Commons license and your intended use is not permitted by statutory regulation or exceeds the permitted use, you will need to obtain permission directly from the copyright holder. To view a copy of this license, visit http://creativecommons. org/licenses/by/4.0/.

\section{References}

1. Ferlay J, Soerjomataram I, Dikshit R, Eser S, Mathers C, Rebelo $\mathrm{M}$, et al. Cancer incidence and mortality worldwide: sources, methods and major patterns in GLOBOCAN 2012. Int J Cancer. 2015;136:E359-86.

2. Varga J, Greten FR. Cell plasticity in epithelial homeostasis and tumorigenesis. Nat Cell Biol. 2017;19:1133-41.

3. Grivennikov SI, Greten FR, Karin M. Immunity, inflammation, and cancer. Cell. 2010;140:883-99.

4. Sica A, Larghi P, Mancino A, Rubino L, Porta C, Totaro MG, et al. Macrophage polarization in tumour progression. Semin Cancer Biol. 2008;18:349-55. 
5. LaPorte SL, Juo ZS, Vaclavikova J, Colf LA, Qi X, Heller NM, et al. Molecular and structural basis of cytokine receptor pleiotropy in the interleukin-4/13 system. Cell. 2008;132:259-72.

6. Heller NM, Qi X, Junttila IS, Shirey KA, Vogel SN, Paul WE, et al. Type I IL-4Rs selectively activate IRS-2 to induce target gene expression in macrophages. Sci Signal. 2008;1:ra17.

7. Fichtner-Feigl S, Strober W, Kawakami K, Puri RK, Kitani A. IL13 signaling through the IL-13alpha2 receptor is involved in induction of TGF-beta1 production and fibrosis. Nat Med. 2006;12:99-106

8. Gandhi NA, Bennett BL, Graham NM, Pirozzi G, Stahl N, Yancopoulos GD. Targeting key proximal drivers of type 2 inflammation in disease. Nat Rev Drug Discov. 2016;15:35-50.

9. Luzina IG, Keegan AD, Heller NM, Rook GA, Shea-Donohue T, Atamas SP. Regulation of inflammation by interleukin-4: a review of "alternatives". J Leukoc Biol. 2012;92:753-64.

10. Mantovani A, Sica A, Sozzani S, Allavena P, Vecchi A, Locati M. The chemokine system in diverse forms of macrophage activation and polarization. Trends Immunol. 2004;25:677-86.

11. Goenka S, Kaplan MH. Transcriptional regulation by STAT6. Immunol Res. 2011;50:87-96.

12. Takeda K, Kamanaka M, Tanaka T, Kishimoto T, Akira S. Impaired IL-13-mediated functions of macrophages in STAT6deficient mice. J Immunol. 1996;157:3220-2.

13. Kaplan MH, Schindler U, Smiley ST, Grusby MJ. Stat6 is required for mediating responses to IL-4 and for development of Th2 cells. Immunity. 1996;4:313-9.

14. Yan D, Wang HW, Bowman RL, Joyce JA. STAT3 and STAT6 signaling pathways synergize to promote cathepsin secretion from macrophages via IRE1alpha activation. Cell Rep. 2016;16:2914-27.

15. Gooch JL, Christy B, Yee D. STAT6 mediates interleukin-4 growth inhibition in human breast cancer cells. Neoplasia. 2002;4:324-31.

16. Cao H, Zhang J, Liu H, Wan L, Zhang H, Huang Q, et al. IL-13/ STAT6 signaling plays a critical role in the epithelialmesenchymal transition of colorectal cancer cells. Oncotarget. 2016;7:61183-98.

17. Das S, Shetty P, Valapala M, Dasgupta S, Gryczynski Z, Vishwanatha JK. Signal Transducer and Activator of Transcription 6 (STAT6) Is a Novel Interactor of Annexin A2 in Prostate Cancer Cells. Biochemistry. 2010;49:2216-26.

18. Jayakumar A, Bothwell ALM. Stat6 Promotes Intestinal Tumorigenesis in a Mouse Model of Adenomatous Polyposis by Expansion of MDSCs and Inhibition of Cytotoxic CD8 Response. Neoplasia. 2017;19:595-605.

19. De Robertis M, Massi E, Poeta ML, Carotti S, Morini S, Cecchetelli L, et al. The AOM/DSS murine model for the study of colon carcinogenesis: From pathways to diagnosis and therapy studies. J Carcinog. 2011;10:9.

20. Clapper ML, Cooper HS, Chang WC. Dextran sulfate sodiuminduced colitis-associated neoplasia: a promising model for the development of chemopreventive interventions. Acta Pharmacol Sin. 2007;28:1450-9.

21. Gordon S, Martinez FO. Alternative activation of macrophages: mechanism and functions. Immunity. 2010;32:593-604.

22. Bollrath J, Phesse TJ, von Burstin VA, Putoczki T, Bennecke M, Bateman T, et al. gp130-mediated Stat3 activation in enterocytes regulates cell survival and cell-cycle progression during colitisassociated tumorigenesis. Cancer Cell. 2009;15:91-102.

23. Whetstone RD, Wittel UA, Michels NM, Gulizia JM, Gold B. Colon carcinogenesis in wild type and immune compromised mice after treatment with azoxymethane, and azoxymethane with dextran sodium sulfate. Mol Carcinog. 2016;55:1187-95.

24. Wali RK, Skarosi S, Hart J, Zhang Y, Dolan ME, Moschel RC, et al. Inhibition of $\mathrm{O}(6)$-methylguanine-DNA methyltransferase increases azoxymethane-induced colonic tumors in rats. Carcinogenesis. 1999;20:2355-60.

25. Schwitalla S, Ziegler PK, Horst D, Becker V, Kerle I, BegusNahrmann Y, et al. Loss of p53 in enterocytes generates an inflammatory microenvironment enabling invasion and lymph node metastasis of carcinogen-induced colorectal tumors. Cancer Cell. 2013;23:93-106.

26. Blackford AN, Jackson SP. ATM, ATR, and DNA-PK: the trinity at the heart of the DNA damage response. Mol Cell. 2017;66:80117.

27. Nishitoh H. CHOP is a multifunctional transcription factor in the ER stress response. J Biochem. 2012;151:217-9.

28. Zhang HS, Chen Y, Fan L, Xi QL, Wu GH, Li XX, et al. The endoplasmic reticulum stress sensor IRE1 alpha in intestinal epithelial cells is essential for protecting against colitis. J Biol Chem. 2015;290:15327-36.

29. Madigan JP, Chotkowski HL, Glaser RL. DNA double-strand break-induced phosphorylation of Drosophila histone variant H2Av helps prevent radiation-induced apoptosis. Nucleic Acids Res. 2002;30:3698-705.

30. Pegoraro G, Kubben N, Wickert U, Gohler H, Hoffmann K, Misteli T. Ageing-related chromatin defects through loss of the NURD complex. Nat Cell Biol. 2009;11:1261-7.

31. Yan SJ, Lim SJ, Shi S, Dutta P, Li WX. Unphosphorylated STAT and heterochromatin protect genome stability. FASEB J. 2011;25:232-41.

32. Peng JC, Karpen GH. Heterochromatic genome stability requires regulators of histone H3 K9 methylation. PLoS Genet. 2009;5: e1000435.

33. Falk M, Lukasova E, Kozubek S. Chromatin structure influences the sensitivity of DNA to gamma-radiation. Biochim Biophys Acta. 2008;1783:2398-414.

34. Dinant C, Luijsterburg MS. The emerging role of HP1 in the DNA damage response. Mol Cell Biol. 2009;29:6335-40.

35. Shi S, Calhoun HC, Xia F, Li J, Le L, Li WX. JAK signaling globally counteracts heterochromatic gene silencing. Nat Genet. 2006;38:1071-6.

36. Dawson MA, Bannister AJ, Gottgens B, Foster SD, Bartke T, Green AR, et al. JAK2 phosphorylates histone H3Y41 and excludes HP1alpha from chromatin. Nature. 2009;461:819-22.

37. Shi S, Larson K, Guo D, Lim SJ, Dutta P, Yan SJ, et al. Drosophila STAT is required for directly maintaining HP1 localization and heterochromatin stability. Nat Cell Biol. 2008;10:489-96.

38. Gurvich N, Tsygankova OM, Meinkoth JL, Klein PS. Histone deacetylase is a target of valproic acid-mediated cellular differentiation. Cancer Res. 2004;64:1079-86.

39. Khan O, La Thangue NB. HDAC inhibitors in cancer biology: emerging mechanisms and clinical applications. Immunol Cell Biol. 2012;90:85-94.

40. Leon-Cabrera SA, Molina-Guzman E, Delgado-Ramirez YG, Vazquez-Sandoval A, Ledesma-Soto Y, Perez-Plasencia CG, et al. Lack of STAT6 attenuates inflammation and drives protection against early steps of colitis-associated colon cancer. Cancer Immunol Res. 2017;5:385-96.

41. Elrod JW, Laroux FS, Houghton J, Carpenter A, Ando T, Jennings $\mathrm{MH}$, et al. DSS-induced colitis is exacerbated in STAT-6 knockout mice. Inflamm Bowel Dis. 2005;11:883-9.

42. Cosin-Roger J, Ortiz-Masia D, Calatayud S, Hernandez C, Esplugues JV, Barrachina MD. The activation of Wnt signaling by a STAT6-dependent macrophage phenotype promotes mucosal repair in murine IBD. Mucosal Immunol. 2016;9:986-98.

43. Greten FR, Eckmann L, Greten TF, Park JM, Li ZW, Egan LJ, et al. IKKbeta links inflammation and tumorigenesis in a mouse model of colitis-associated cancer. Cell. 2004;118:285-96.

44. Grivennikov SI, Wang K, Mucida D, Stewart CA, Schnabl B, Jauch $\mathrm{D}$, et al. Adenoma-linked barrier defects and microbial 
products drive IL-23/IL-17-mediated tumour growth. Nature. 2012;491:254-8.

45. Pallangyo CK, Ziegler PK, Greten FR. IKKbeta acts as a tumor suppressor in cancer-associated fibroblasts during intestinal tumorigenesis. J Exp Med. 2015;212:2253-66.

46. Taniguchi K, Wu LW, Grivennikov SI, de Jong PR, Lian I, Yu FX, et al. A gp130-Src-YAP module links inflammation to epithelial regeneration. Nature. 2015;519:57-62.

47. Liu L, Nishihara R, Qian ZR, Tabung FK, Nevo D, Zhang X, et al. Association between inflammatory diet pattern and risk of colorectal carcinoma subtypes classified by immune responses to tumor. Gastroenterology. 2017;153:1517-30 e14.

48. Tauriello DVF, Palomo-Ponce S, Stork D, Berenguer-Llergo A, Badia-Ramentol J, Iglesias $\mathrm{M}$, et al. TGFbeta drives immune evasion in genetically reconstituted colon cancer metastasis. Nature. 2018;554:538-43.

49. Hanahan D, Weinberg RA. Hallmarks of cancer: the next generation. Cell. 2011;144:646-74.

50. Elinav E, Nowarski R, Thaiss CA, Hu B, Jin C, Flavell RA. Inflammation-induced cancer: crosstalk between tumours, immune cells and microorganisms. Nat Rev Cancer. 2013;13:759-71.

51. Li WX. Canonical and non-canonical JAK-STAT signaling. Trends Cell Biol. 2008;18:545-51.
52. Barski A, Cuddapah S, Cui K, Roh TY, Schones DE, Wang Z, et al. High-resolution profiling of histone methylations in the human genome. Cell. 2007;129:823-37.

53. Herbert DR, Holscher C, Mohrs M, Arendse B, Schwegmann A, Radwanska $\mathrm{M}$, et al. Alternative macrophage activation is essential for survival during schistosomiasis and downmodulates $\mathrm{T}$ helper 1 responses and immunopathology. Immunity. 2004; 20:623-35.

54. Takeda K, Kaisho T, Yoshida N, Takeda J, Kishimoto T, Akira S. Stat3 activation is responsible for IL-6-dependent $\mathrm{T}$ cell proliferation through preventing apoptosis: Generation and characterization of $\mathrm{T}$ cell-specific Stat3-deficient mice. J Immunol. 1998;161:4652-60.

55. Madison BB, Dunbar L, Qiao XT, Braunstein K, Braunstein E, Gumucio DL. Cis elements of the villin gene control expression in restricted domains of the vertical (crypt) and horizontal (duodenum, cecum) axes of the intestine. J Biol Chem. 2002;277:3327583.

56. Diamanti MA, Gupta J, Bennecke M, De Oliveira T, Ramakrishnan M, Braczynski AK, et al. IKKalpha controls ATG16L1 degradation to prevent ER stress during inflammation. J Exp Med. 2017;214:423-37. 